\title{
Lattice distortion of solute atoms in metals studied by x-ray-absorption fine structure
}

\author{
U. Scheuer and B. Lengeler \\ Institut für Festkörperforschung, Forschungszentrum Jülich, D-5170 Jülich, Germany
}

(Received 14 February 1991)

\begin{abstract}
The analysis of the $x$-ray-absorption fine structure (XAFS) yields information about the local atomic arrangement of the absorbing atom. The technique was used to study systematically the lattice dilatation or compression caused by substitutional impurity atoms in the fcc metals $\mathrm{Al}, \mathrm{Cu}, \mathrm{Ni}, \mathrm{Pd}$, and $\mathrm{Ag}$ and the bcc metals $\mathrm{Fe}, \mathrm{Nb}$, and $\mathrm{V}$. Measuring XAFS spectra at the $K$ and $L$ edges of a variety of metals, interatomic distances, coordination numbers, and Debye-Waller factors were determined. Using experimentally determined amplitudes and phases from appropriate model compounds, the accuracy of the analysis is about $0.5 \%$ for nearest-neighbor distances and about $10 \%$ for coordination numbers and Debye-Waller factors. For the 61 systems investigated, shifts of the first-neighbor-shell distance of up to $10 \mathrm{pm}$ are found, while the shifts of higher shells are generally small. Systematic variations within the rows of the Periodic Table are observed, indicating the importance of electronic effects. The results are discussed in comparison with lattice-parameter measurements and band-structure calculations.
\end{abstract}

\section{INTRODUCTION}

Technologically important properties of metals and semiconductors are largely influenced by structural and chemical defects. A large variety of experimental methods, many of them diffraction techniques (using $\mathrm{x}$ rays, neutrons, or electrons), has been used to study them. With the advance of synchrotron radiation, absorption spectroscopy has emerged as an additional tool for the study of geometric and electronic structures of defects in solids. In this paper we want to describe an $\mathrm{x}$ ray-absorption fine-structure (XAFS) study of the lattice distortion of impurity atoms substituted in a host metal. One aim of the paper is to show the capabilities of the method as well as the difficulties encountered in this technique. The other aim is to provide a data base for the test of theoretical calculations.

Randomly distributed solute atoms expand or compress the host lattice and change the average lattice parameter, measured, e.g., by x-ray diffraction. However, the local distortion near the impurity will generally be different in magnitude or sign, depending on the coordination shell involved. It can be measured by XAFS. This technique gives insight into the strain fields of solutes and can be used to obtain information on the elastic interaction potentials of atoms in an alloy. The elastic strain influences the interaction of solute atoms with other defects (e.g., dislocations) as well as the tendency towards long-range ordering or clustering. Therefore, it contributes to the basic understanding of alloy formation and behavior. In the last years, the theoretical concepts describing the properties of electronic ground states of ideal crystals and ordered alloys have greatly improved. ${ }^{1,2}$ Starting from the atomic numbers of the elements involved, self-consistent $a b$ initio calculations can determine band structures, cohesive energies, lattice parameters, and lattice structures in satisfactory agreement with experimental data. It also became possible to determine lattice distortions by impurity atoms in metals using local-density-functional theory and the Korringa-KohnRostoker (KKR) Green's-function method. ${ }^{3}$ XAFS can provide a unique data base for the systematic comparison of experiments and band-structure calculations. In order to perform this comparison, five fcc host metals (aluminum, copper, nickel, palladium, and silver) and three bcc metals (iron, niobium, and vanadium) were chosen. The impurity atoms were chosen from the three long rows of the Periodic Table to study the influence of successive filling of electronic shells.

\section{EXPERIMENTAL}

Dilute substitutional binary alloys of $\mathrm{Al}, \mathrm{Cu}, \mathrm{Ni}, \mathrm{Pd}$, and $\mathrm{Ag}$ were investigated. For the $\mathrm{Pd}$ matrix, $\mathrm{Fe}, \mathrm{Co}, \mathrm{Ni}$, $\mathrm{Cu}$, and $\mathrm{Ga}$ were chosen from the first long row of the Periodic Table; $\mathrm{Y}, \mathrm{Zr}, \mathrm{Nb}, \mathrm{Mo}, \mathrm{Ru}$, and $\mathrm{Rh}$ from the second row; and $\mathrm{Hf}, \mathrm{Pt}, \mathrm{Au}, \mathrm{Pb}$, and $\mathrm{Bi}$ from the third row. Additionally, the rare-earth elements $\mathrm{Sm}, \mathrm{Eu}, \mathrm{Gd}$, $\mathrm{Yb}$, and $\mathrm{Lu}$ and the actinides $\mathrm{Th}$ and $\mathrm{U}$ were selected. In a similar manner, $\mathrm{Ti}, \mathrm{Mn}, \mathrm{Fe}, \mathrm{Ni}, \mathrm{Ga}$, and $\mathrm{Ge}$ (first row); $\mathrm{Pd}, \mathrm{Ag}, \mathrm{In}$, and Sn (second row); and $\mathrm{Au}$ and Pt from the third row were chosen for the $\mathrm{Cu}$ matrix. In $\mathrm{Ni}$, the solutes investigated were $\mathrm{Ti}, \mathrm{V}, \mathrm{Cr}, \mathrm{Mn}, \mathrm{Fe}, \mathrm{Co}, \mathrm{Ga}, \mathrm{Ge}$; $\mathrm{Nb}, \mathrm{Mo}, \mathrm{Pd}, \mathrm{In} ; \mathrm{Pt}$ and $\mathrm{Au}$. In $\mathrm{Al}$, only the first row elements $\mathrm{Mn}, \mathrm{Cu}, \mathrm{Zn}, \mathrm{Ga}$, and $\mathrm{Ge}$ were studied. In addition, the alloy of the neighboring elements AgPd and the bcc systems $\mathrm{FeCr}, \mathrm{FeMn}, \mathrm{NbAu}, \mathrm{NbZr}$, and $V \mathrm{Ti}$ were investigated. In Table I, these 61 systems are listed together with the solute concentrations as determined from the weight of the constituents. These solute concentrations are generally between 1 and 2 at. \%, which is well suited for XAFS transmission experiments. The concentrations had to be kept below about 2 at. \% to avoid short-range order or even clustering of the solutes. In those cases where the solubility is too small, lower concentrations were used. For $C u \mathrm{In}, C u \mathrm{Sn}, \mathrm{FeMn}$, and for the Al alloys, the solute concentration was less than 1 at. \%. For the binary systems $C u \mathrm{Fe}, C u \mathrm{Co}, C u \mathrm{In}$, and $C u \mathrm{Sn}$, the solute 
TABLE I. Impurity type and concentration, $c_{0}$; nearest-neighbor distance, $r_{1}$; and shift compared to pure host metal, $\Delta r_{1}$, as determined by XAFS, model system, applied correction, $r_{c}$; and shifts calculated from the data by King (Ref 23), by Pearson (Ref. 6), and taken from Abraham et al. (Ref. 3).

\begin{tabular}{|c|c|c|c|c|c|c|c|c|}
\hline & & & & Host $\mathbf{P d}$ & & & & \\
\hline Solute & $c_{0}$ & $r_{1}(\mathrm{pm})$ & $\Delta r_{1}(\mathrm{pm})$ & Model & $r_{c}$ & $\begin{array}{c}\Delta r_{1} \\
\text { King } \\
\end{array}$ & $\begin{array}{c}\Delta r_{1} \\
\text { Pearson } \\
\end{array}$ & $\begin{array}{c}\Delta r_{1} \\
\text { Abraham } \\
\end{array}$ \\
\hline $\mathrm{Fe}$ & 2.00 & 271.7 & $-2.9 \pm 0.3$ & $\mathrm{Pd}_{3} \mathrm{Fe}$ & 0 & -1.6 & & \\
\hline Co & 2.14 & 270.6 & $-3.9 \pm 0.7$ & $\mathrm{Pd}_{3} \mathrm{Fe}$ & -0.7 & -2.1 & & \\
\hline $\mathrm{Ni}$ & 2.00 & 269.4 & $-5.1 \pm 1.0$ & $\mathrm{Pd}_{47} \mathrm{Cu}_{53}$ & 0.6 & -1.9 & & \\
\hline $\mathrm{Cu}$ & 2.01 & 268.7 & $-5.9 \pm 0.4$ & $\mathrm{Pd}_{47} \mathrm{Cu}_{53}$ & 0 & -2.5 & & \\
\hline $\mathrm{Ga}$ & 2.07 & 273.2 & $-1.4 \pm 1.5$ & $\mathrm{Pd}_{47} \mathrm{Cu}_{53}$ & -1.2 & & & \\
\hline $\mathrm{Ga}$ & 2.07 & 274.6 & $0.1 \pm 2.0$ & $\mathrm{Pd}_{3} \mathrm{Fe}$ & -3.0 & & & \\
\hline $\mathrm{Y}$ & 2.00 & 280.9 & $6.3 \pm 0.4$ & $\mathrm{Pd}_{3} \mathrm{Y}$ & 0 & & & 9.4 \\
\hline $\mathrm{Zr}$ & 2.06 & 274.9 & $0.4 \pm 0.4$ & $\mathrm{Pd}_{3} \mathrm{Zr}$ & 0 & 3.6 & 3.2 & 3.5 \\
\hline $\mathrm{Nb}$ & 2.12 & 271.8 & $-2.8 \pm 0.3$ & $\mathrm{Pd}_{3} \mathrm{Nb}$ & 0 & 0.8 & 0.7 & -0.9 \\
\hline Mo & 2.11 & 269.8 & $-4.7 \pm 1.0$ & $\mathrm{Pd}_{3} \mathrm{Nb}$ & -0.7 & -0.6 & -0.6 & -3.0 \\
\hline $\mathrm{Ru}$ & 2.16 & 271.8 & $-2.7 \pm 0.9$ & $P d$ & 1.4 & -1.1 & -1.2 & -2.7 \\
\hline $\mathrm{Rh}$ & 1.75 & 272.1 & $-2.5 \pm 1.0$ & $\mathbf{P d}$ & 0.7 & -0.7 & -0.8 & -1.3 \\
\hline $\mathrm{Sm}$ & 3.23 & 282.3 & $7.8 \pm 0.3$ & $\mathrm{Pd}_{3} \mathrm{Sm}$ & 0 & & & \\
\hline $\mathrm{Eu}$ & 1.70 & 281.3 & $6.7 \pm 0.3$ & $\mathrm{Pd}_{3} \mathrm{Eu}$ & 0 & & & \\
\hline Gd & 2.28 & 282.0 & $7.5 \pm 0.8$ & $\mathrm{Pd}_{3} \mathrm{Gd}$ & 0 & & & \\
\hline $\mathrm{Yb}$ & 2.25 & 278.4 & $3.9 \pm 0.8$ & $\mathrm{Pd}_{3} \mathrm{Lu}$ & 0.5 & & & \\
\hline $\mathbf{L u}$ & 2.22 & 278.7 & $4.2 \pm 0.5$ & $\mathrm{Pd}_{3} \mathrm{Lu}$ & 0 & & & \\
\hline Hf & 1.72 & 274.2 & $-0.3 \pm 0.4$ & $\mathrm{Pd}_{3} \mathrm{Hf}$ & 0 & & & \\
\hline $\mathbf{P t}$ & 1.64 & 273.4 & $-1.1 \pm 1.0$ & $\mathbf{P d}_{3} \mathrm{~Pb}$ & 2.0 & 0.2 & 0.1 & \\
\hline $\mathrm{Au}$ & 1.92 & 275.4 & $0.9 \pm 0.8$ & $\mathrm{Pd}_{3} \mathrm{~Pb}$ & -1.5 & 2.2 & 2.0 & \\
\hline $\mathrm{Pb}$ & 2.00 & 278.5 & $4.0 \pm 0.3$ & $\mathrm{Pd}_{3} \mathrm{~Pb}$ & 0 & 5.2 & & \\
\hline $\mathbf{P b}$ & 2.23 & 278.0 & $3.4 \pm 0.3$ & $\mathrm{Pd}_{3} \mathrm{~Pb}$ & 0 & & & \\
\hline $\mathrm{Pb}$ & 2.30 & 277.7 & $3.2 \pm 0.4$ & $\mathrm{Pd}_{3} \mathrm{~Pb}$ & 0 & & & \\
\hline $\mathbf{B i}$ & 2.44 & 279.3 & $4.8 \pm 1.0$ & $\mathrm{Pd}_{3} \mathrm{~Pb}$ & -0.5 & 7.0 & & \\
\hline Th & 2.00 & 284.3 & $9.8 \pm 0.4$ & $\mathrm{Pd}_{3} \mathrm{Th}$ & 0 & & & \\
\hline $\mathbf{U}$ & 2.00 & 275.6 & $1.1 \pm 0.4$ & $\begin{array}{c}\mathrm{Pd}_{3} \mathrm{U} \\
\text { Host } \mathrm{Cu}\end{array}$ & 0 & 1.3 & & \\
\hline $\mathrm{Ti}$ & 2.00 & 258.3 & $3.5 \pm 1.0$ & $\mathrm{Ni}_{3} \mathrm{Ti}$ & -1.8 & 4.1 & & 7.4 \\
\hline Mn & 1.00 & 256.8 & $2.0 \pm 1.0$ & $\mathrm{Ni}_{3} \mathrm{Mn}$ & -1.2 & 5.5 & 4.0 & 2.5 \\
\hline Mn & 1.00 & 256.4 & $1.6 \pm 2.0$ & $\mathrm{Cu}$ & 1.8 & & & \\
\hline $\mathrm{Fe}$ & 1.00 & 253.7 & $-1.2 \pm 1.0$ & $\mathrm{Ni}_{3} \mathrm{Fe}$ & -1.2 & 0.7 & & 0.4 \\
\hline $\mathrm{Fe}$ & 1.00 & 253.3 & $-1.5 \pm 1.1$ & $\mathrm{Cu}$ & 2.1 & & & \\
\hline $\mathrm{Fe}$ & 2.30 & 255.2 & $0.4 \pm 1.2$ & $\mathrm{Ni}_{3} \mathrm{Fe}$ & -1.2 & & & \\
\hline $\mathrm{Fe}$ & 2.30 & 255.1 & $0.2 \pm 1.5$ & $\mathrm{Cu}$ & 2.1 & & & \\
\hline Co & 1.00 & 254.5 & $-0.3 \pm 1.8$ & $\mathrm{Cu}$ & 1.4 & -0.6 & & -1.2 \\
\hline $\mathrm{Ni}$ & 1.00 & 253.0 & $-1.8 \pm 0.7$ & $\mathrm{Ni}$ & -1.1 & -1.4 & -1.3 & -1.2 \\
\hline $\mathrm{Ni}$ & 1.00 & 253.1 & $-1.7 \pm 1.2$ & $\mathrm{Cu}$ & 0.7 & & & \\
\hline $\mathrm{Ni}$ & 2.00 & 252.5 & $-2.3 \pm 0.7$ & $\mathrm{Ni}$ & -1.1 & & & \\
\hline $\mathrm{Ni}$ & 2.00 & 252.8 & $-2.0 \pm 1.0$ & $\mathrm{Cu}$ & 0.7 & & & \\
\hline $\mathrm{Ga}$ & 1.00 & 257.6 & $2.8 \pm 1.1$ & $\mathrm{Ni}_{3} \mathrm{Ga}$ & 0.9 & 3.9 & 3.5 & \\
\hline $\mathrm{Ga}$ & 1.00 & 258.6 & $3.7 \pm 0.9$ & $\begin{array}{c}\mathrm{Ni}_{3} \mathrm{Ga} \\
\mathrm{Cu}\end{array}$ & 0 & & & \\
\hline $\mathrm{Ge}$ & 4.00 & 256.5 & $1.6 \pm 0.9$ & $\mathrm{Ni}_{3} \mathrm{Ge}$ & -0.9 & 4.4 & 3.9 & 2.6 \\
\hline $\mathrm{Ge}$ & 4.00 & 257.0 & $2.1 \pm 0.8$ & $\mathrm{Cu}$ & -2.1 & & & \\
\hline $\mathbf{P d}$ & 1.00 & 258.6 & $3.8 \pm 0.6$ & $\mathrm{Cu}_{53} \mathbf{P d}_{47}$ & 0 & 4.5 & & \\
\hline $\mathbf{P d}$ & 2.00 & 258.6 & $3.8 \pm 0.4$ & $\mathrm{Cu}_{53} \mathrm{Pd}_{47}$ & 0 & & & \\
\hline $\mathrm{Ag}$ & 1.00 & 260.9 & $6.1 \pm 0.7$ & $\mathrm{Cu}_{53} \mathrm{Pd}_{47}$ & -0.7 & 7.0 & & \\
\hline $\mathrm{Ag}$ & 2.00 & 261.3 & $6.5 \pm 0.9$ & $\mathrm{Cu}_{53} \mathrm{Pd}_{47}$ & -0.7 & & & \\
\hline In & 0.62 & 262.8 & $8.0 \pm 0.7$ & $\mathrm{Ni}_{3} \mathrm{In}$ & -0.7 & 12.7 & & \\
\hline Sn & 0.57 & 261.3 & $6.5 \pm 0.7$ & $\mathrm{Ni}_{3} \mathrm{Sn}$ & -1.0 & 13.4 & & \\
\hline $\mathbf{P t}$ & 1.00 & 259.6 & $4.8 \pm 0.8$ & $\mathrm{Ni}_{3} \mathrm{Pt}$ & -1.0 & 5.0 & 4.2 & \\
\hline $\mathbf{P t}$ & 1.00 & 258.7 & $3.9 \pm 0.5$ & $\mathrm{Cu}_{3} \mathrm{Au}$ & 0.6 & & & \\
\hline $\mathrm{Au}$ & 1.00 & 259.6 & $4.8 \pm 0.4$ & $\mathrm{Cu}_{3} \mathrm{Au}$ & 7.6 & 6.3 & & \\
\hline $\mathrm{Au}$ & 5.00 & 261.1 & $6.3 \pm 0.4$ & $\mathrm{Cu}_{3} \mathrm{Au}$ & 0 & & & \\
\hline
\end{tabular}


TABLE I. (Continued).

\begin{tabular}{|c|c|c|c|c|c|c|c|c|}
\hline \multicolumn{9}{|c|}{ Host $\mathrm{Ni}$} \\
\hline Solute & $c_{0}$ & $r_{1}(\mathrm{pm})$ & $\Delta r_{1}(\mathrm{pm})$ & Model & $r_{c}$ & $\begin{array}{c}\Delta r_{1} \\
\text { King } \\
\end{array}$ & $\begin{array}{c}\Delta r_{1} \\
\text { Pearson } \\
\end{array}$ & $\begin{array}{c}\Delta r_{1} \\
\text { Abraham } \\
\end{array}$ \\
\hline $\mathrm{Ti}$ & 2.00 & 250.8 & $2.2 \pm 0.4$ & $\mathrm{Ni}_{3} \mathrm{Ti}$ & 0 & 3.5 & & 6.1 \\
\hline $\mathrm{V}$ & 2.00 & 247.9 & $-0.7 \pm 1.1$ & $\mathrm{Ni}_{3} \mathrm{Ti}$ & -0.7 & 1.6 & & 1.5 \\
\hline $\mathrm{Cr}$ & 2.46 & 247.6 & $-1.1 \pm 0.7$ & $\mathrm{Ni}_{3} \mathrm{Mn}$ & 0.7 & 1.2 & & 0.0 \\
\hline Mn & 2.00 & 250.9 & $2.3 \pm 0.4$ & $\mathrm{Ni}_{3} \mathrm{Mn}$ & 0 & 2.8 & 3.0 & 1.6 \\
\hline $\mathrm{Fe}$ & 2.01 & 248.8 & $0.2 \pm 0.3$ & $\mathrm{Ni}_{3} \mathrm{Fe}$ & 0 & 1.3 & & 0.1 \\
\hline Co & 2.00 & 248.2 & $-0.4 \pm 0.6$ & $\mathrm{Ni}$ & 0.7 & 0.3 & & -0.7 \\
\hline $\mathrm{Ga}$ & 3.29 & 252.0 & $3.3 \pm 1.0$ & $\mathrm{Ni}_{3} \mathrm{Ga}$ & 0 & 2.0 & & \\
\hline $\mathrm{Ge}$ & 2.90 & 249.8 & $1.2 \pm 0.3$ & $\mathrm{Ni}_{3} \mathrm{Ge}$ & 0 & 1.8 & & 1.7 \\
\hline $\mathrm{Nb}$ & 2.00 & 254.1 & $5.4 \pm 0.7$ & $\mathrm{Ni}_{3} \mathrm{Nb}$ & 0 & 6.1 & & \\
\hline $\mathrm{Nb}$ & 2.00 & 253.5 & $4.9 \pm 0.9$ & $\mathrm{Ni}_{4} \mathrm{Mo}$ & 0.6 & & & \\
\hline Mo & 2.00 & 251.0 & $2.4 \pm 0.3$ & $\mathrm{Ni}_{4} \mathrm{Mo}$ & 0 & 2.6 & 3.0 & \\
\hline $\mathbf{P d}$ & 2.00 & 253.8 & $5.2 \pm 0.3$ & $\mathrm{Cu}_{53} \mathrm{Pd}_{47}$ & 1.0 & 4.9 & & \\
\hline In & 1.50 & 256.9 & $8.3 \pm 0.3$ & $\mathrm{Ni}_{3} \mathrm{In}$ & 0 & 4.4 & & \\
\hline $\mathbf{P t}$ & 2.00 & 255.4 & $6.7 \pm 0.3$ & $\mathrm{Ni}_{3} \mathrm{Pt}$ & 0 & 5.4 & 4.8 & \\
\hline $\mathbf{P t}$ & 2.00 & 254.7 & $6.1 \pm 0.9$ & $\mathrm{Cu}_{3} \mathrm{Au}$ & 2.1 & & & \\
\hline $\mathbf{A u}$ & 1.97 & 256.8 & $8.2 \pm 1.0$ & $\mathrm{Cu}_{3} \mathrm{Au}$ & -0.8 & 7.6 & 6.0 & \\
\hline $\mathrm{Au}$ & 1.97 & 257.7 & $9.1 \pm 0.9$ & $\mathrm{Ni}_{3} \mathrm{Pt}$ & 1.0 & & & \\
\hline \multicolumn{9}{|c|}{ Host Al } \\
\hline Mn & 0.50 & 275.0 & $-9.9 \pm 2.0$ & $\mathrm{Mg}_{2} \mathrm{Ge}$ & -0.5 & -5.4 & & \\
\hline $\mathrm{Cu}$ & 0.50 & 279.2 & $-5.7 \pm 0.7$ & $\theta^{\prime}-\mathrm{AlCu}$ & 0 & -4.4 & & \\
\hline $\mathrm{Cu}$ & 1.00 & 278.0 & $-6.9 \pm 0.7$ & $\theta^{\prime}-\mathrm{AlCu}$ & 0 & & & \\
\hline $\mathrm{Cu}$ & 1.50 & 276.0 & $-8.9 \pm 0.5$ & $\theta^{\prime}-\mathrm{AlCu}$ & 0 & & & \\
\hline $\mathrm{Cu}$ & 2.30 & 275.4 & $-9.5 \pm 0.5$ & $\theta^{\prime}-\mathrm{AlCu}$ & 0 & & & \\
\hline $\mathrm{Zn}$ & 1.00 & 284.0 & $-0.9 \pm 2.0$ & $\mathrm{Mg}_{2} \mathrm{Ge}$ & 2.0 & -0.7 & & \\
\hline $\mathrm{Ga}$ & 0.50 & 287.0 & $2.1 \pm 1.0$ & $\theta^{\prime}-\mathrm{AlCu}$ & -1.0 & 0.6 & & \\
\hline $\mathrm{Ge}$ & 0.30 & 287.7 & $2.8 \pm 0.8$ & $\mathrm{Mg}_{2} \mathrm{Ge}$ & 0 & 1.5 & & \\
\hline $\mathrm{Ge}$ & 0.70 & 287.0 & $2.1 \pm 0.6$ & $\mathrm{Mg}_{2} \mathrm{Ge}$ & 0 & & & \\
\hline $\mathrm{Ge}$ & 1.00 & 287.5 & $2.6 \pm 0.5$ & $\mathrm{Mg}_{2} \mathrm{Ge}$ & 0 & & & \\
\hline $\mathrm{Ge}$ & 1.50 & 288.2 & $3.3 \pm 0.5$ & $\mathrm{Mg}_{2} \mathrm{Ge}$ & 0 & & & \\
\hline \multicolumn{9}{|c|}{ Host $\mathrm{Ag}$} \\
\hline $\mathbf{P d}$ & 0.98 & 285.4 & $-2.5 \pm 0.5$ & $\mathrm{Ag}$ & 0.5 & & & \\
\hline $\mathbf{P d}$ & 0.98 & 285.4 & $-2.5 \pm 0.6$ & $\mathbf{P d}$ & -0.7 & & & \\
\hline \multicolumn{9}{|c|}{ Host $\mathrm{Fe}$} \\
\hline $\mathrm{Mn}$ & 0.84 & 247.7 & $0.1 \pm 0.8$ & $\mathrm{Fe}$ & 0.7 & & & \\
\hline $\mathrm{Cr}$ & 1.38 & 246.3 & $-1.3 \pm 1.5$ & $\mathrm{Cr}$ & -2.6 & & & \\
\hline $\mathrm{Cr}$ & 1.38 & 247.2 & $-0.4 \pm 1.2$ & $\mathrm{Fe}$ & 1.4 & & & \\
\hline \multicolumn{9}{|c|}{ Host $\mathrm{Nb}$} \\
\hline $\mathrm{Zr}$ & 2.00 & 291.2 & $5.8 \pm 0.6$ & $\mathrm{Zr}$ & 0 & & & \\
\hline $\mathrm{Au}$ & 2.00 & 289.8 & $4.4 \pm 0.6$ & $\mathrm{Nb}_{3} \mathrm{Au}$ & 0 & & & \\
\hline \multicolumn{9}{|c|}{ Host V } \\
\hline $\mathrm{Ti}$ & 2.00 & 265.4 & $4.1 \pm 1.0$ & $V$ & 0.7 & & & \\
\hline
\end{tabular}

concentration was near the solubility limit. These samples where quenched from $1073 \mathrm{~K}$ into water to prevent decomposition of the alloy. In a number of cases $(A l \mathrm{Cu}$, $A l \mathrm{Ge}, C u \mathrm{Ag}, C u \mathrm{Au}, C u \mathrm{Fe}, C u \mathrm{Ni}, C u \mathrm{Pd})$, several alloys with different concentrations where produced in order to check for unmixing or clustering effects. The results will be discussed in some detail for the cases of $A l \mathrm{Ge}$ and the metastable alloy $\mathrm{AlCu}$.

Phases and amplitudes for the XAFS analysis were extracted from model systems. Therefore, appropriate intermetallic compounds for each dilute alloy were prepared. In order to show the transferability of phases 
and amplitudes from the model compounds, ordered $\mathrm{AuCu}$ (tetragonal $\mathrm{AuCu}-\mathrm{I}$ structure) was fitted with phases and amplitudes from $\mathrm{Cu}_{3} \mathrm{Au}$ and $\mathrm{Au}$ metal. $\mathrm{A}$ very good fit was obtained with $(8.2 \pm 1.0) \mathrm{Cu}$ neighbors at a distance of $(269.4 \pm 0.5) \mathrm{pm}$ and (3.9 \pm 1.1$) \mathrm{Au}$ neighbors at $(279.7 \pm 0.6) \mathrm{pm}$ from the absorbing $\mathrm{Au}$ atom. These values compare well with the literature data $^{4}$ giving $8 \mathrm{Cu}$ neighbors at $269.4 \mathrm{pm}$ and $4 \mathrm{Au}$ atoms at $279.5 \mathrm{pm}$. In Table II, model compounds and pure metals used for the data evaluation are listed. Also listed is the number and distance of first and second neighbors. For the compound $A_{n} B_{m}$, this is a $B-A$ distance in the first shell and a $B-B$ distance in the second shell, unless otherwise noted in the table. The interatomic distances

TABLE II. List of model compounds $A_{n} B_{m}$ and pure elements used for the XAFS analysis. Listed are crystallographic structure type, sample type [foil $(F)$ or powder $(P)$ ], interatomic distances, and coordination numbers for first and second shell.

\begin{tabular}{|c|c|c|c|c|c|c|}
\hline Model & Structure & Sample & $r_{1}(\mathrm{pm})$ & $N_{1}$ & $r_{2}(\mathrm{pm})$ & $N_{2}$ \\
\hline $\mathrm{Ag}$ & $\mathrm{Cu}$ & $F$ & 287.9 & 12 & 407.1 & 6 \\
\hline Al & $\mathrm{Cu}$ & $F$ & 284.9 & 12 & 402.9 & 6 \\
\hline AlCo & $\mathrm{CsCl}$ & $P$ & 246.3 & 8 & 284.4 & 6 \\
\hline $\mathrm{AlNi}$ & $\mathrm{CsCl}$ & $P$ & 246.0 & 8 & 284.1 & 6 \\
\hline$\theta^{\prime}-\mathrm{AlCu}$ & $\left(\mathrm{CaF}_{2}\right)$ & $F$ & 248.7 & 8 & 406.1 & 12 \\
\hline $\mathrm{Au}$ & $\mathrm{Cu}$ & $F$ & 287.5 & 12 & 406.6 & 6 \\
\hline $\mathrm{Au}_{3} \mathrm{Cu}$ & $\mathrm{Cu}_{3} \mathrm{Au}$ & $F$ & 280.8 & 12 & 397.1 & 6 \\
\hline $\mathrm{AuCu}$ & AuCuI & $F$ & 272.8 & $\begin{array}{r}8 \mathrm{Au} \\
+4 \mathrm{Cu}\end{array}$ & 385.6 & $\begin{array}{r}4 \mathrm{Au} \\
+2 \mathrm{Cu}\end{array}$ \\
\hline $\mathrm{Cr}$ & W & $P$ & 249.2 & 8 & 287.8 & 6 \\
\hline $\mathrm{Cu}$ & $\mathrm{Cu}$ & $F$ & 254.8 & 12 & 360.4 & 6 \\
\hline $\mathrm{Cu}_{3} \mathrm{Au}$ & $\mathrm{Cu}_{3} \mathrm{Au}$ & $F$ & 263.8 & 12 & 373.1 & 6 \\
\hline $\mathrm{Cu}_{53} \mathrm{Pd}_{47}$ & $\mathrm{CsCl}$ & $F$ & 256.8 & 8 & 296.5 & 6 \\
\hline $\mathrm{Fe}$ & W & $F$ & 247.6 & 8 & 285.9 & 6 \\
\hline $\mathrm{Mg}_{2} \mathrm{Ge}$ & $\mathrm{CaF}_{2}$ & $P$ & 275.4 & 8 & 449.6 & 12 \\
\hline $\mathrm{Nb}$ & W & $F$ & 285.4 & 8 & 329.5 & 6 \\
\hline $\mathrm{Nb}_{3} \mathrm{Au}$ & $\beta-\mathrm{W}$ & $P$ & 290.2 & 12 & 449.6 & 6 \\
\hline $\mathrm{Ni}$ & $\mathrm{Cu}$ & $F$ & 248.6 & 12 & 351.6 & 6 \\
\hline $\mathrm{Ni}_{3} \mathrm{Fe}$ & $\mathrm{Cu}_{3} \mathrm{Au}$ & $P$ & 250.9 & 12 & 354.8 & 6 \\
\hline $\mathrm{Ni}_{3} \mathrm{Ga}$ & $\mathrm{Cu}_{3} \mathrm{Au}$ & $P$ & 252.7 & 12 & 357.4 & 6 \\
\hline $\mathrm{Ni}_{3} \mathrm{Ge}$ & $\mathrm{Cu}_{3} \mathrm{Au}$ & $P$ & 251.8 & 12 & 356.0 & 6 \\
\hline $\mathrm{Ni}_{3} \mathrm{In}$ & $\mathrm{Cu}_{3} \mathrm{Au}$ & $P$ & 264.3 & 12 & 375.0 & 6 \\
\hline $\mathrm{Ni}_{3} \mathrm{Mn}$ & $\mathrm{Cu}_{3} \mathrm{Au}$ & $P$ & 253.1 & 12 & 358.0 & 6 \\
\hline $\mathrm{Ni}_{4} \mathrm{Mo}$ & $\mathrm{Ni}_{4} \mathrm{Mo}$ & $F$ & 254.2 & 12 & 359.4 & $\begin{array}{r}4 \mathrm{Ni} \\
+2 \mathrm{Mo}\end{array}$ \\
\hline $\mathrm{Ni}_{3} \mathrm{Nb}$ & $\mathrm{Cu}_{3} \mathrm{Ti}$ & $P$ & 259.5 & 12 & 365.3 & 6 \\
\hline $\mathrm{Ni}_{3} \mathrm{Pt}$ & $\mathrm{Cu}_{3} \mathrm{Au}$ & $P$ & 257.7 & 12 & 364.5 & 6 \\
\hline $\mathrm{Ni}_{3} \mathrm{Sn}$ & $\mathrm{Ni}_{3} \mathrm{Sn}$ & $P$ & 262.8 & 12 & 381.0 & 6 \\
\hline $\mathrm{Ni}_{3} \mathrm{Ti}$ & $\mathrm{Ni}_{3} \mathrm{Ti}$ & $P$ & 254.2 & 12 & 435.2 & $\begin{array}{r}6 \mathrm{Ni} \\
+2 \mathrm{Ti}\end{array}$ \\
\hline $\mathbf{P d}$ & $\mathrm{Cu}$ & $F$ & 274.5 & 12 & 388.2 & 6 \\
\hline $\mathrm{Pd}_{47} \mathrm{Cu}_{53}$ & $\mathrm{CsCl}$ & $F$ & 256.8 & 8 & 296.5 & 6 \\
\hline $\mathrm{Pd}_{3} \mathrm{Eu}$ & $\mathrm{Cu}_{3} \mathrm{Au}$ & $P$ & 288.5 & 12 & 408.0 & 6 \\
\hline $\mathrm{Pd}_{3} \mathrm{Fe}$ & $\mathrm{Cu}_{3} \mathrm{Au}$ & $P$ & 271.1 & 12 & 384.3 & 6 \\
\hline $\mathrm{Pd}_{3} \mathrm{Gd}$ & $\mathrm{Cu}_{3} \mathrm{Au}$ & $P$ & 288.6 & 12 & 408.2 & 6 \\
\hline $\mathrm{Pd}_{3} \mathrm{Hf}$ & $\mathrm{Ni}_{3} \mathrm{Ti}$ & $P$ & 279.6 & 12 & 477.0 & $\begin{array}{r}6 \mathrm{Pd} \\
+2 \mathrm{Hf}\end{array}$ \\
\hline $\mathrm{Pd}_{3} \mathrm{Lu}$ & $\mathrm{Cu}_{3} \mathrm{Au}$ & $P$ & 284.3 & 12 & 402.0 & 6 \\
\hline $\mathrm{Pd}_{3} \mathrm{Nb}$ & $\mathrm{Al}_{3} \mathrm{Ti}$ & $P$ & 276.3 & 12 & 388.6 & 4 \\
\hline $\mathrm{Pd}_{3} \mathrm{~Pb}$ & $\mathrm{Cu}_{3} \mathrm{Au}$ & $P$ & 283.8 & 12 & 401.4 & 6 \\
\hline $\mathrm{Pd}_{3} \mathrm{Sm}$ & $\mathrm{Cu}_{3} \mathrm{Au}$ & $P$ & 289.5 & 12 & 409.4 & 6 \\
\hline $\mathrm{Pd}_{3} \mathrm{Th}$ & $\mathrm{Ni}_{3} \mathrm{Ti}$ & $P$ & 294.8 & 12 & 507.3 & 6 \\
\hline $\mathrm{Pd}_{3} \mathrm{U}$ & $\mathrm{Ni}_{3} \mathrm{Ti}$ & $P$ & 289.9 & 12 & 493.9 & $\begin{array}{r}6 \mathrm{Pd} \\
+2 \mathrm{U}\end{array}$ \\
\hline $\mathrm{Pd}_{4} \mathrm{U}$ & $\mathrm{Cu}_{3} \mathrm{Au}$ & $P$ & 286.5 & 12 & 405.2 & 6 \\
\hline $\mathbf{P d}_{3} \mathbf{Y}$ & $\mathrm{Cu}_{3} \mathrm{Au}$ & $P$ & 287.4 & 12 & 406.4 & 6 \\
\hline $\mathrm{Pd}_{3} \mathrm{Zr}$ & $\mathrm{Ni}_{3} \mathrm{Ti}$ & $P$ & 280.7 & 12 & 478.9 & $\begin{array}{r}6 \mathrm{Pd} \\
+2 \mathrm{Zr}\end{array}$ \\
\hline$V$ & $W$ & $F$ & 261.2 & 8 & 301.7 & 6 \\
\hline $\mathrm{Zr}$ & $\mathrm{Mg}$ & $F$ & 320.2 & 12 & 547.9 & 8 \\
\hline
\end{tabular}


in Table II are given for a temperature of $77 \mathrm{~K}$. If no measurement was available at this temperature in the standard literature, ${ }^{4-8}$ the lattice spacing was interpolated according to the thermal expansion coefficients of the elements. ${ }^{9}$ Any change of these distances (e.g., due to more accurate measurements) would cause corresponding changes of the XAFS results.

The alloys were produced from high-purity materials by melting with inductive heating in a cold crucible under a high-purity Ar atmosphere. The binary alloys were slowly cooled to room temperature. Subsequently they were rolled to the desired thickness, with some annealing steps to remove the effects of cold work, if necessary. Several alloys mentioned above were annealed and quenched to room temperature after rolling. The model compounds were annealed for long times below the ordering temperature to ensure a degree of long-range order close to unity. However, it sometimes turned out to be difficult or in the case of $\mathrm{Au}_{3} \mathrm{Cu}$ even impossible to obtain $S=1$. A part of the model compounds was ground into fine powder and held in place using adhesive Kapton tape. Another part was rolled to the desired thickness, marked $F$ in Table 2. Generally, the rolled foils gave better and more reproducible results due to the absence of pinholes. Furthermore, the thickness variation was lower and thickness control easier than for the powders. For foils as well as for powder samples, the thickness was close to the optimum thickness given by $1 / \mu(E)$, with $\mu(E)$ the absorption coefficient of the material at an energy just above the solute atom's edge. The optimum thickness varied from $6 \mu \mathrm{m}$ for NiTi to $170 \mu \mathrm{m}$ for $A l \mathrm{Ge}$.

The XAFS measurements were carried out at the RÖMO1 beam line of the Hamburger Synchrotron Strahlungslabor (HASYLAB). A double crystal system was used to monochromatize the radiation. Silicon $\{111\}$ crystals were used for energies between 4.9 ( $\mathrm{Ti} K$ edge) and $9.0 \mathrm{keV}(\mathrm{Cu} K$ edge), while $\mathrm{Si}\{311\}$ crystals were used for higher energies up to $29.2 \mathrm{keV}$ ( $\mathrm{Sn} K$ edge). For $\{111\}$ crystals, the energy resolution is between 0.6 and $2.0 \mathrm{eV}$ for this energy range. For $\{311\}$ crystals, the energy resolution is $1.0,2.9$, and $11.2 \mathrm{eV}$ at 9,15 , and 29.2 $\mathrm{keV}$, respectively. These numbers are similar to the energy spread due to the finite lifetime of the core hole [Ti $K$, $0.9 \mathrm{eV}$; Cu $K, 1.5 \mathrm{eV}$; Rb $K, 3.4 \mathrm{eV}$; Sn $K, 9.2 \mathrm{eV}$ (Refs. 10 and 11)]. The second crystal was slightly detuned to reject harmonic contributions. We estimate the contribution of the third harmonic to be less than $10^{-4}$ even at 5 $\mathrm{keV}$. Incident and transmitted intensities were measured using ionization chambers. A reference material (this is a substance with a well-known edge position) was measured between the second and a third ionization chamber. It allows one to calibrate the energy scale within $\pm 0.1 \mathrm{eV}$. The ionization chambers were filled with mixtures of $\mathrm{N}_{2}$ and Ar or He. The partial pressures of the gases were selected according to the energy so that the first chamber absorbed about $10 \%$ of the incoming photon flux and the second chamber about $90 \%$ of the transmitted flux. The energy was scanned in steps of about $0.5 \mathrm{eV}$ in the vicinity of the edge and in steps of about $2 \mathrm{eV}$ well above and below the edge. The experiment was fully controlled by a Digital Equipment Corporation micro VAX computer.

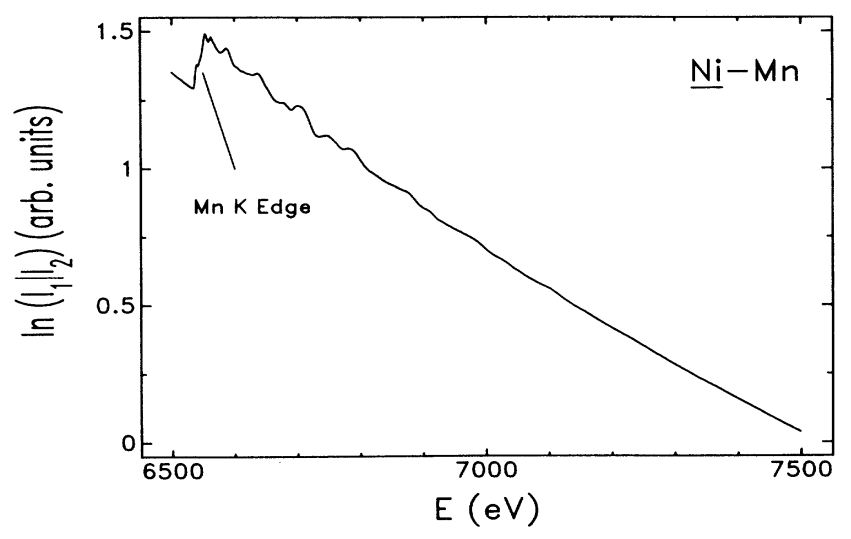

FIG. 1. X-ray absorption at the $\mathrm{Mn} K$ edge in a dilute $\mathrm{Ni}-2.0$ at. \% $\mathrm{Mn}$ alloy, measured in transmission at $77 \mathrm{~K}$.

All spectra were recorded at $77 \mathrm{~K}$ in order to reduce thermal damping of the XAFS oscillations. The samples were mounted on aluminum frames which were immersed in liquid nitrogen in order to keep exchange and cooling times short. The synchrotron beam passed through the sample $15 \mathrm{~mm}$ above the level of liquid nitrogen. In favorable cases (low concentrations, low- $Z$ solute in high- $Z$ matrix, no fluorescence from the matrix), XAFS was measured in fluorescence mode using a largearea $p$ - $i$ - $n$-type photodiode (Hamamatsu S3594). Fluorescence measurements of $N b A u, P d \mathrm{Y}, P d \mathrm{Ru}, P d \mathrm{Th}$, and $P d \mathrm{U}$, however, proved to be less satisfactory than transmission measurements because they are more prone to systematic errors. In the transmission mode, solute concentrations as low as 0.3 at. \% could be measured with good accuracy. The high signal-to-noise ratio (see Figs. 1 and 2) is attributed to the mechanical stability and careful assembly of the ion chambers (thus avoiding leak currents and microphonic sensitivity). Furthermore, the use of short low-noise wires between ion chambers and the Keithley $\mathrm{K} 427$ amplifiers was found advantageous.

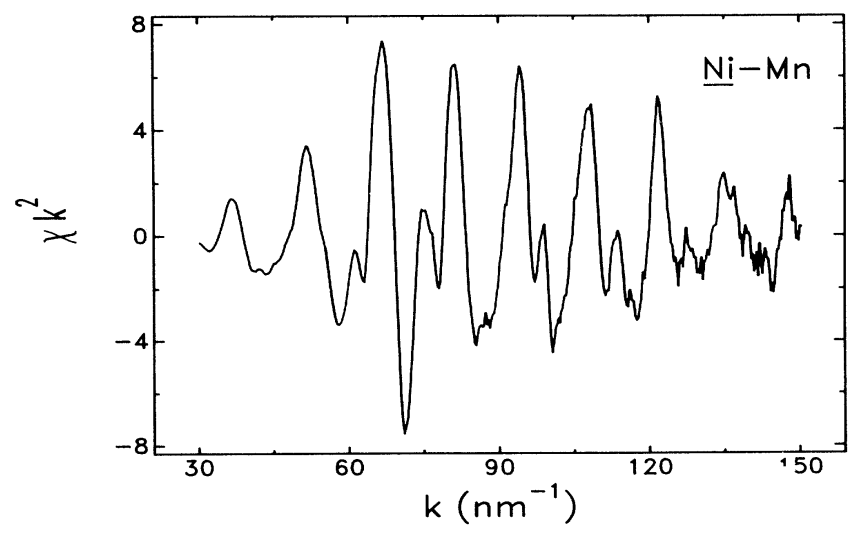

FIG. 2. XAFS signal $\chi(k) k^{2}$ at the Mn $K$ edge from Fig. 1. 


\section{DATA EVALUATION AND RESULTS}

In order to extract structural information from the spectra, the standard procedure described in Ref. 12 was used. It will be demonstrated for the lattice distortion around a $\mathrm{Mn}$ atom in a $\mathrm{Ni}$ matrix. The transmission spectrum measured at the Mn $K$ edge is shown in Fig. 1. In a first step, the oscillating contribution $\chi(k)$ is isolated from the total absorption coefficient $\mu(k)$. The lowfrequency background is removed from the higherfrequency XAFS signal by means of cubic spline functions. $\chi$ is a function of the photoelectron wave vector $k$ given by $k=\sqrt{2 m\left(E-E_{0}\right)} / \hbar$, where $E_{0}$ is the threshold energy. In a first approximation, $E_{0}$ is set equal to the first inflection point of the edge. It is treated as an adjustable parameter in the further analysis. $\chi(k)$ is then normalized using the edge height $J$ and the factor $\left[1-\left(8 k^{2} a^{2}\right) / 3\right]$, with $a=\hbar / 2 m E_{0} \cdot{ }^{12}$ It is then multiplied by a weighting factor $k^{n}(n=1,2,3)$. Only data above $k=25 \mathrm{~nm}^{-1}$ are used because the low- $k$ part of the spectrum is not well described by the simple XAFS theory. The resulting XAFS signal $\chi(k) k^{2}$, shown in Fig. 2 , is then Fourier transformed in order to separate the contributions from the various shells. The Fourier transform (Fig. 3) shows peaks from at least four coordination shells. The peak positions, however, are shifted to lower distances when compared to the actual atomic positions in the crystal due to effects of the scattering phase shift. The contributions of individual shells can be separated by means of a filter (dotted line in Fig. 3). A smooth window function with slopes proportional to $[1-\cos (\pi / r)]$ is used. The filtered contribution is then transformed back into $k$ space (Fig. 4).

Phase and amplitude information is necessary to obtain interatomic distances and coordination numbers. Detailed calculations are available ${ }^{13}$ which give a good qualitative description of the phase shift of the photoelectron in the absorber and backscatterer, as well as for the backscattering amplitude. Nevertheless, experimentally determined phases and amplitude have a number of advantages. The XAFS formula (for a review see Ref. 14) is de-

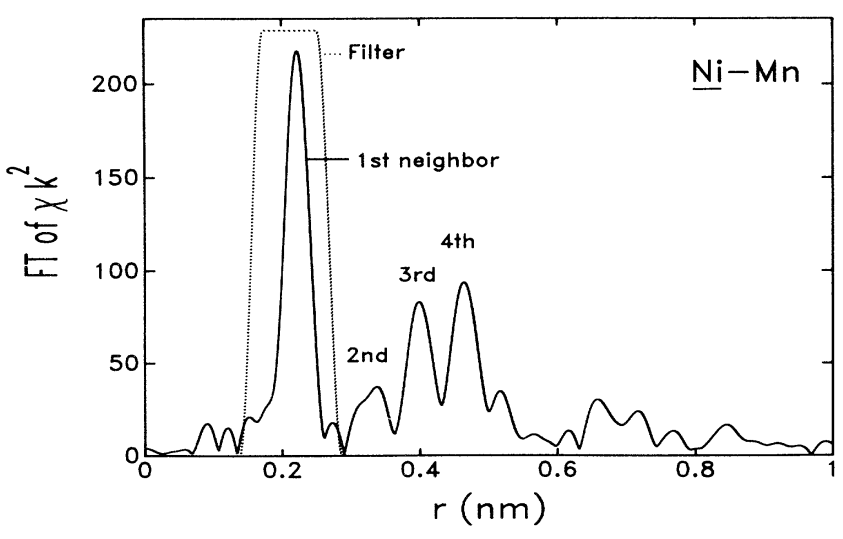

FIG. 3. Fourier transform of the XAFS signal $\chi(k) k^{2}$ from Fig. 2. Four neighbor shells are indicated. The contribution of the first shell is separated by a filter function (dotted curve).

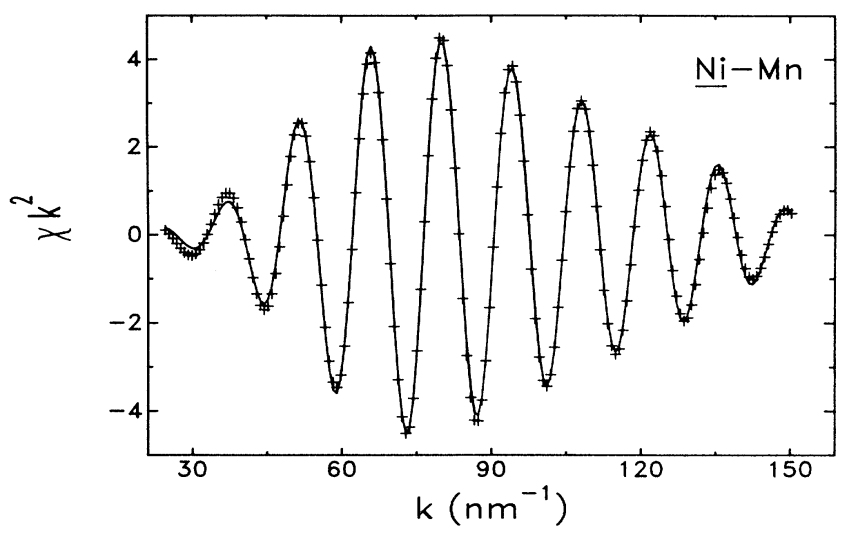

FIG. 4. Fit of the first-shell contribution from Fig. $3(+)$ with phases and amplitudes from $\mathrm{Ni}_{3} \mathrm{Mn}(-)$.

rived under a number of assumptions (plane-wave approximation, single scattering only). Furthermore, the energy $E_{0}$ is not well established. There is good reason to assume that these effects are similar in a well-chosen model and the system under investigation and that in a first approximation they cancel out.

In several cases, there is no appropriate model available for a given pair of absorber and backscatterer. It has been shown ${ }^{15}$ that compounds from neighboring elements in the Periodic Table can be used. The errors are small and linear with the difference in atomic number, $\delta Z$. They can easily be corrected if $\delta Z$ is only a few atomic numbers. This correction is listed below with the results in Table I. The errors are much larger if the backscatterer is exchanged for a neighboring element, because then phases and amplitudes are different in the model and the system to be analyzed. Therefore, pure $\mathrm{Cu}$ would be a better model for the system $\mathrm{Cu}-\mathrm{Ni}$ than $\mathrm{Ni}$. Generally, the model compounds should be chemically similar to the system under investigation, and they should have welldefined and well-known neighbor shells. For the NiMn alloy, $\mathrm{Ni}_{3} \mathrm{Mn}$ is an appropriate model because the first shell is identical with the dilute alloy (a Mn atom surrounded by $12 \mathrm{Ni}$ neighbors). The fit of the first-shell contribution with phases and amplitudes from $\mathrm{Ni}_{3} \mathrm{Mn}$ is shown in Fig. 4. It turns out that the nearest $\mathrm{Ni}$ neighbors around the $\mathrm{Mn}$ atom are shifted outwards by $2.3 \pm 0.4 \mathrm{pm}$. This is a change of $0.9 \%$ when compared to pure Ni. The coordination number turns is $N_{1}=12.1 \pm 1.0$ The distance to the second neighbors is the same as in pure nickel within the accuracy of the data (about $\pm 1.5 \mathrm{pm}$ ).

The errors quoted are derived from the parameter range of the least-squares fitting procedure and from a comparison of repeated measurements of the sample under various operating conditions of the beam line and, if available, of fits using different model compounds. An error estimation for the NiMn system is illustrated in Fig. 5. It shows the increase of the least-squares difference $s$ between measurement and fit if one parameter [interatomic distance (bottom), coordination number (middle), Debye-Waller factor (top)] is fixed to a specific value while the other parameters are adjusted in order to op- 


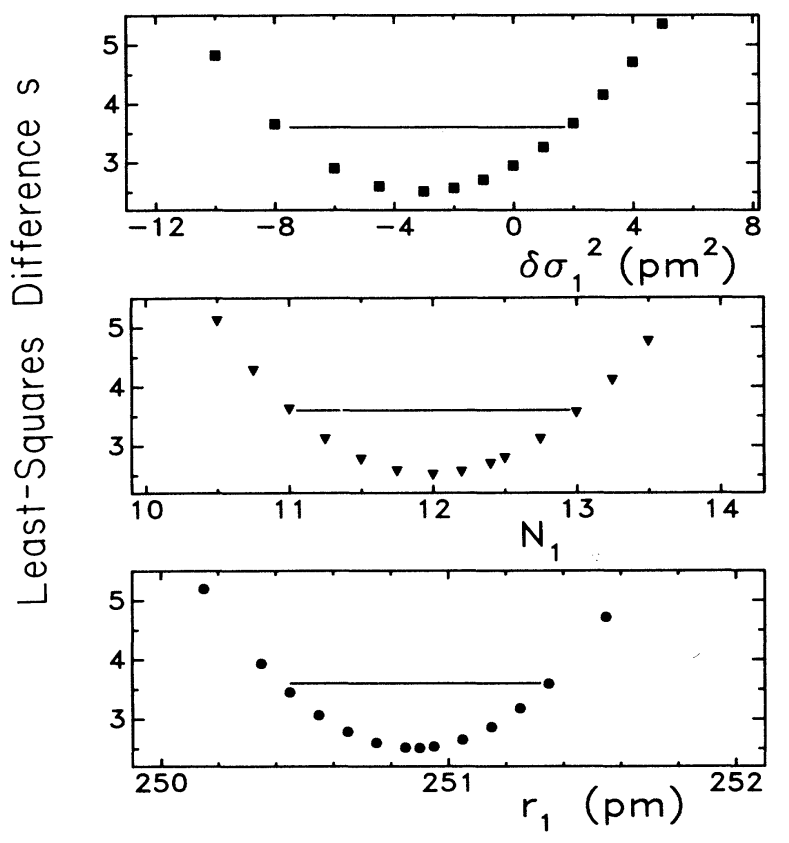

FIG. 5. Increase of least-squares difference between measurement and fit if one parameter is fixed to a specific value while the other parameters are adjusted in order to optimize the fit. Data from NiMn, Fig. 4. Bottom: First-neighbor distance fixed, Middle: Coordination number fixed. Top: Debye-Waller factor fixed. Horizontal bars give error estimate if condition $s=s_{\min } \sqrt{2}$ is chosen.

timize the fit. For a given value of the least-squares difference, an error estimate for the three parameters can be determined. Here the criterion $s=s_{\min } \sqrt{2}$ is used, where $s_{\min }$ is the result of the best fit. In Fig. 5, the accuracy of nearest-neighbor determination is found to be $\pm 0.4 \mathrm{pm}$, while the error of the coordination number is about \pm 1 and the difference of the squares of the DebyeWaller factors of the model and system under investigation is $\delta \sigma^{2}=-3.1 \pm 5 \mathrm{pm}^{2}$. In the fitting procedure, the interatomic distance is only weakly correlated to either coordination number or Debye-Waller factor, while these two factors are strongly correlated. ${ }^{12}$ This is the reason why the accuracy of the distance determination is much better than that of coordination number.

The complete list of the results for first shell distances is given in Table I. Along with the interatomic distance $r_{1}$ and the shift compared to the pure metal $\Delta r_{1}$, the model compound and the applied correction, $r_{c}$, if any, is given. A number of special cases will be discussed below. In order to illustrate difficulties encountered in the evaluation procedure, the cases of $\mathrm{Ge}$ and $\mathrm{Cu}$ solutes in aluminum shall be presented. ${ }^{16,17}$ Alloys with different compositions were prepared. The compositions were $0.3,0.7$, 1.0 , and 1.5 at. \% for $A l \mathrm{Ge}$. The solubility of $\mathrm{Ge}$ in $\mathrm{Al}$ is about 2 at. $\%$ at $700 \mathrm{~K} .{ }^{18}$ The alloys were quenched from $700 \mathrm{~K}$ into a eutectic mixture of water and hydrochloric acid at $213 \mathrm{~K}$ and stored in liquid nitrogen in order to freeze in vacancy migration. Since there is no appropriate compound of $\mathrm{Al}$ and $\mathrm{Ge}, \mathrm{Mg}_{2} \mathrm{Ge}$ was used (see Tables
I and II). The XAFS evaluation shows (Fig. 6, Table I) that for Al-0.3 at. \% Ge, the first-neighbor shell of a $\mathrm{Ge}$ atom is $287.7 \mathrm{pm}$ apart, an increase of $2.8 \mathrm{pm}$ when compared to pure $\mathrm{Al}(284.9 \mathrm{pm}$ at $77 \mathrm{~K})$. For the other concentrations up to 1.5 at. $\%$, the first-neighbor distance is identical within experimental error $( \pm 0.5 \mathrm{pm})$. It has to be concluded that the quenching process is sufficiently fast to prevent alloy decomposition at room temperature.

$A l \mathrm{Cu}$ alloys were prepared with compositions of 0.5 , $1.0,2.0$, and 2.3 at. $\% \mathrm{Cu}$. The solubility of $\mathrm{Cu}$ in $\mathrm{Al}$ at $820 \mathrm{~K}$ is about 2.5 at. $\%$ and about 0.1 at. $\%$ at room temperature. ${ }^{19}$ For higher concentrations, decomposition proceeds via Guinier-Preston (GP) zones, $\theta^{\prime}$ and $\theta^{\prime \prime}$ to the $\theta$ phase $\mathrm{CuAl}_{2}{ }^{20}$ The alloys were quenched from $813 \mathrm{~K}$ in a manner similar to $A l \mathrm{Ge}$. The result of the analysis is shown in Fig. 6. The small $\mathrm{Cu}$ atom contracts the first $\mathrm{Al}$ shell. Contrary to $A l \mathrm{Ge}$, the shift depends on the $\mathrm{Cu}$ concentration. The first-shell distance decreases from $279.2 \mathrm{pm}$ for 0.5 at. $\% \mathrm{Cu}$ to $275.4 \mathrm{pm}$ for 2.3 at. $\% \mathrm{Cu}$. Extrapolating this linear relationship to $0 \% \mathrm{Cu}$ yields a first-shell distance around a $\mathrm{Cu}$ atom of $280.0 \mathrm{pm}$, a lattice contraction of $4.9 \pm 0.5 \mathrm{pm}$ compared to pure $\mathrm{Al}$ (dashed line in Fig. 6). This trend is attributed to shortrange order in the as-quenched alloy. This conclusion is supported by the measured coordination numbers. For the alloy $\mathrm{Al}-2.3$ at. $\% \mathrm{Cu}$, between one and two $\mathrm{Cu}$ atoms are found in the first shell of a $\mathrm{Cu}$ atom, in agreement with the observation of $\mathrm{Cu}$ clusters by diffuse $\mathrm{x}$-ray scattering in $\mathrm{Al}-1.7$ at. $\% \mathrm{Cu}$ at $793 \mathrm{~K} .{ }^{21}$ The importance of the thermal history of these metastable alloys is stressed by conflicting experimental results. ${ }^{17,22}$ Annealing samples containing GP zones ${ }^{17}$ at $473 \mathrm{~K}$ for times between 35 and $3300 \mathrm{~s}$ leads to drastic changes of the interatomic distances (open circles in Fig. 6). After annealing for less than $100 \mathrm{~s}$, interatomic distances similar to the supersaturated solution are found, due to the dissolution of the GP zones ("reversion"). Upon prolonged annealing, a different state of decomposition is reached as shown by a $2.9 \%$ drop of the first-neighbor distance. The results of Fontaine et al. ${ }^{22}$ are presumably caused by the occurrence of GP zones rather than a solid solution.

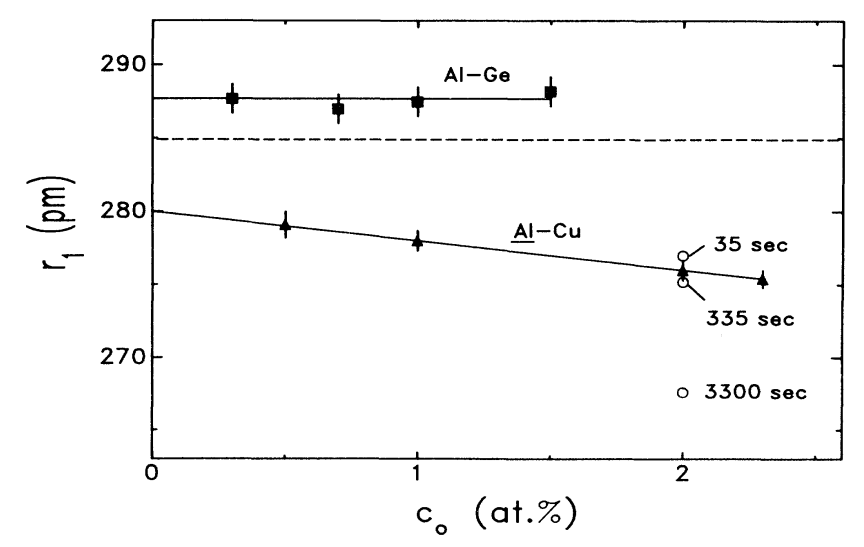

FIG. 6. Interatomic distances determined by XAFS for $A l \mathrm{Ge}$ $(\square)$ and $A l \mathrm{Cu}(\Delta)$ alloys and for an $A l C u$ alloy containing GP zones (O) after three annealing steps at $473 \mathrm{~K}$ (Ref. 17). Dashed line: pure aluminum. 
Similar to $A l \mathrm{Ge}, C u \mathrm{Ni}, C u \mathrm{Pd}$, and $C u \mathrm{Ag}$ do not show a change of interatomic distance with solute concentration. $C u F e$, on the other hand, shows an increase of the first-shell distance with $\mathrm{Fe}$ concentration (see Table I). For $\mathrm{CuAu}$, higher interatomic distances are observed if the $\mathrm{Au}$ concentration is as high as 5 at. \%. However, aside from the local lattice distortion, a solute atom substituted into a crystal leads to an overall increase of the crystal lattice parameter. For $\mathrm{CuAu}$, the change can be estimated from the data by King. ${ }^{23}$ For an addition of 1 at. $\% \mathrm{Au}$, an increase of the first-shell distance of about $0.4 \mathrm{pm}$ is calculated. The addition of 5 at. \% Au causes an increase of $1.8 \mathrm{pm}$. Comparing the interatomic distances as determined by XAFS to this expanded lattice parameter gives a corrected shift of about $4.5 \mathrm{pm}$ for both concentrations. For the other systems investigated, the lattice-parameter change is within the error limits.

For the analysis of the $P d U$ system, the two model compounds $\mathrm{Pd}_{3} \mathrm{U}$ and $\mathrm{Pd}_{4} \mathrm{U}$ are available. Good fits, however, were obtained with $\operatorname{Pd}_{3} \mathrm{U}$ only. This compound melts congruently, while $\mathrm{Pd}_{4} \mathrm{U}$ melts peritectically, making the phase pureness questionable. Analyzing $\mathbf{P d}_{4} \mathrm{U}$ with phases and amplitudes from $\mathrm{Pd}_{3} \mathrm{U}$ did not give good fits with values consistent with literature data.

The analysis of five bcc alloys (see Table I) posed special problems. In bcc crystals, the second shell is only $15 \%$ farther away than the first shell. This makes it hard to clearly separate them in the Fourier transform. In fcc crystals, the second shell is $41 \%$ farther away. In ideal hcp crystals (i.e., $c / a \approx 1.63$ ), the first two subshells are sufficiently close to treat them as one shell with 12 atoms. The next two subshells can similarity be treated as one, being well separated from the first one. These are favorable circumstances for an XAFS investigation of the close-packed crystals. As an example for the analysis of a bcc system, the data for $\mathrm{NbAu}$ are shown in Figs. 7 and 8. The XAFS signal is calculated as $\chi k^{3}$. This gives a better separation of first- and second-shell peaks in the Fourier transform (Fig. 7). The data are fitted well (Fig. 8) with phases and amplitudes from $\mathrm{Nb}_{3} \mathrm{Au}$, which has a $\beta$-W

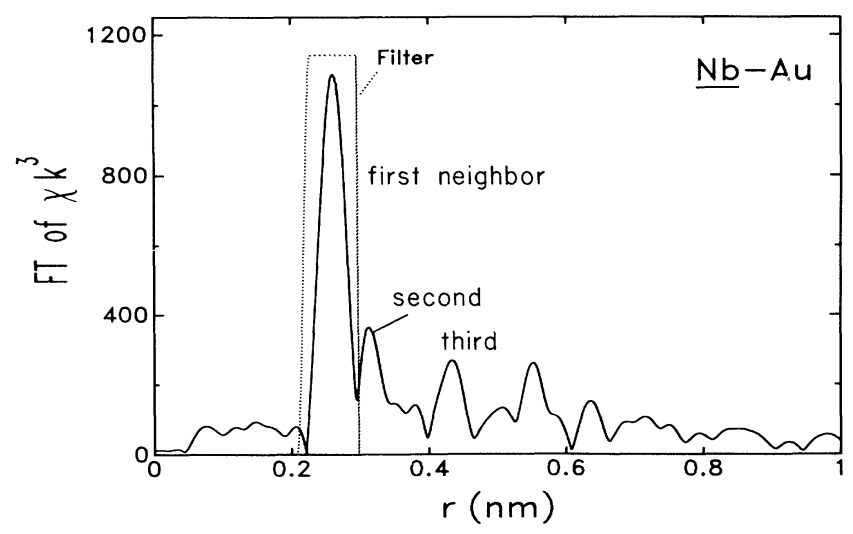

FIG. 7. Fourier transform of XAFS signal $\chi(k) k^{3}$ for bcc NbAu. Three neighbor shells are indicated. The contribution of the first shell is separated by a filter function (dotted curve).

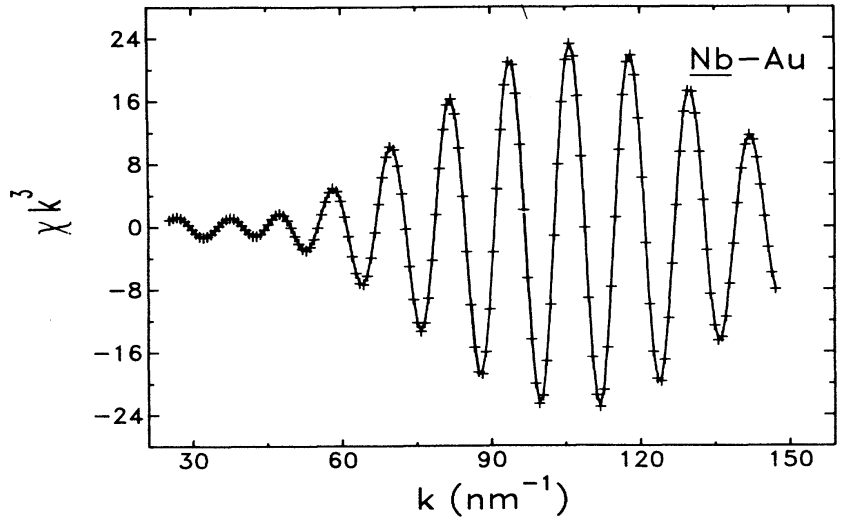

FIG. 8. Fit of the first-shell contribution from $\mathrm{NbAu}(+)$ with phases and amplitudes from $\mathrm{Nb}_{3} \mathrm{Au}(-)$.

structure with 12 nearest neighbors in the first shell. The first-neighbor shift is $4.4 \pm 0.6 \mathrm{pm}$.

Particular caution is advised if model and system have different symmetry. Some worsening of the fits and a larger error, particularly for the coordination numbers, is expected. For $\mathrm{NbAu}$ mentioned above, the coordination number comes out too high $\left(N_{1} \approx 19\right)$. Another case is the compound $\mathrm{Cu}_{53} \mathrm{Pd}_{47}$ used for $C u \mathrm{Pd}, C u \mathrm{Ag}$, and $N i \mathrm{Pd}$. In one case, $P d C o$, no reliable results could be obtained with this model. For similar reasons, bcc $\mathrm{V}$ is a much better model for $V \mathrm{Ti}$ than hcp $\mathrm{Ti}$ in spite of the problems with the bcc structure mentioned above. The use of $\mathrm{Nb}$ as a model for $\mathrm{NbZr}$ did not give good-quality fits. As discussed in Ref. 24, the phases were transferred from $\mathrm{Zr}$ and the backscattering amplitude taken from the $\mathrm{Nb}$ metal. In a similar manner, the quality of the fit for the fcc system $\mathrm{CuGa}$ could be improved by using phases from $\mathrm{Ni}_{3} \mathrm{Ga}$ and amplitudes from $\mathrm{Cu}$ metal (see Table I).

A number of related publications should be mentioned. Raoux et al. ${ }^{25}$ have studied the lattice distortion in $\mathrm{Al}-3$ at. \% $\mathrm{Mg}$ and found a change of the first-neighbor distance of $8.0 \pm 1.5 \mathrm{pm}$. Mimault et al. ${ }^{26}$ studied $A l \mathrm{Zn}$ and found a decrease of the interatomic distance of $-2.0 \pm 1.0$ pm. Room-temperature measurements of $\mathrm{Ti}-0.5$ at. \% $\mathrm{Cu}$ by $\mathrm{Marcus}^{27}$ showed a decrease of the $\mathrm{Ti}-\mathrm{Cu}$ bond length of $-5.0 \pm 4.5 \mathrm{pm}$ when compared to the average bond length in pure $\mathrm{Ti}$. Munch et al. ${ }^{28}$ found a rise of the first-neighbor distance in $\mathrm{Cr}-1$ at. \% of 5 pm (no errors given). Stearns ${ }^{29}$ measured the lattice distortion of a number of $4 s p$ and $5 s p$ elements in Fe. The following changes of the interatomic distances are given: $\mathrm{Fe}-\mathrm{Ge}$, $5 \pm 2 \mathrm{pm}, \mathrm{Fe}$-As, $3 \pm 2 \mathrm{pm}, \mathrm{Fe}-\mathrm{Sn}, 6 \pm 2 \mathrm{pm}, \mathrm{Fe}-\mathrm{Sb}, 10 \pm 3$ pm. Renaud et al. ${ }^{30}$ studied $\mathrm{Au}_{1-x} \mathrm{Ni}_{x}$ solid solutions. For the dilute alloy $\mathrm{Ni}-1$ at. $\% \mathrm{Au}$, a lattice expansion of $6.4 \pm 1.0 \mathrm{pm}$ is reported. For the alloy $\mathrm{Au}-1$ at. $\% \mathrm{Ni}$, a lattice contraction of $-5.6 \pm 1.5 \mathrm{pm}$ is found. Hastings et al. $^{31}$ used fluorescent techniques to study a $\mathrm{Cu}-75$ ppm Fe alloy and found a decrease of the first-neighbor distance of $-1.6 \pm 1.0 \mathrm{pm}$. Dilute alloys of $\mathrm{Cu}$ and $\mathrm{Ag}$ containing 1 at. \% Pd were studied by Weightman et $a l .{ }^{32}$ In $\mathrm{CuPd}$, the nearest-neighbor distance increases $5 \pm 1 \mathrm{pm}$, while in $\mathrm{AgPd}$, little change of the nearest- 
neighbor distance $(-1 \pm 1 \mathrm{pm})$ within the error limits is found. Craievich et al. ${ }^{33}$ found a lattice expansion of 6.8 $\mathrm{pm}$ (no error given) around an $\mathrm{Ag}$ atom in a $\mathrm{CuAg}-4$ at. \% Ag alloy. Cohen et al. ${ }^{34}$ reports a lattice expansion in $\mathrm{CuSn}-0.3$ at. \% Sn and $\mathrm{CuSn}-1$ at. \% $\mathrm{Sn}$ of about $7 \pm 2 \mathrm{pm}$. Measurements by Mikkelsen et al. ${ }^{35}$ show that, in $\mathrm{Cu}-5$ at. \% $\mathrm{Au}$, the first-neighbor distance is increased by $10 \pm 1 \mathrm{pm}$, while in $A u \mathrm{Cu}-5$ at. $\% \mathrm{Cu}$, the first-neighbor distance decreases by $-4 \pm 1 \mathrm{pm}$. Finally, Mikkelson and Boyce ${ }^{36}$ have measured $\mathrm{Ga}_{1-x} \operatorname{In}_{x}$ As solid solutions. For Ga-As bonds, a linear increase of the nearest-neighbor distance with $x$ is found, with a maximum of $4 \pm 1 \mathrm{pm}$ for $x=1$. The In-As bond length also increases with $x$, with a minimum of $-4 \pm 1 \mathrm{pm}$ for $x=0$. For As-As pairs, two bond lengths are found, depending on whether As-Ga-As or As-In-As atoms are involved. In the dilute limits, very little lattice distortion is found. A similar study has been performed by the authors ${ }^{37}$ for the systems (Ga,In)P, (Ga,In)Sb, Ga(P,As), and $\mathrm{Zn}(\mathrm{Se}, \mathrm{Te})$.

The measurements on $A l \mathrm{Zn},{ }^{26} \mathrm{NiAu},{ }^{30} \mathrm{CuFe},{ }^{31} \mathrm{CuPd}$, $A g P d,{ }^{32} \mathrm{CuAg},{ }^{33}$ and $\mathrm{CuSn}$ (Ref. 34) show good quantitative agreement with the results presented here within the accuracy of the data. The disagreement concerning $A l \mathrm{Cu}$ alloys ${ }^{22}$ has been discussed already. Furthermore, the results by Mikkelson et al. ${ }^{35}$ on $\mathrm{CuAu}$ are clearly larger than our results.

\section{DISCUSSION}

In order to show the general trend of our results, the lattice distortion caused by first row elements in $\mathrm{Ni}, \mathrm{Cu}$, and $\mathrm{Pd}$ is shown in Fig. 9. The magnitude and sign of the first-shell shift depend on the lattice spacing of the host material. The large Pd lattice is contracted by the $3 d$ elements up to $-6 \mathrm{pm}(P d \mathrm{Cu})$ when compared to pure $\mathrm{Pd}$. The Ni lattice, on the other hand, is rather expanded locally by the solute atom up to $3 \mathrm{pm}(\mathrm{NiGa})$. A roughly parabolic shape is found as a function of atomic number $Z$. A minimum lattice expansion (or maximum lattice

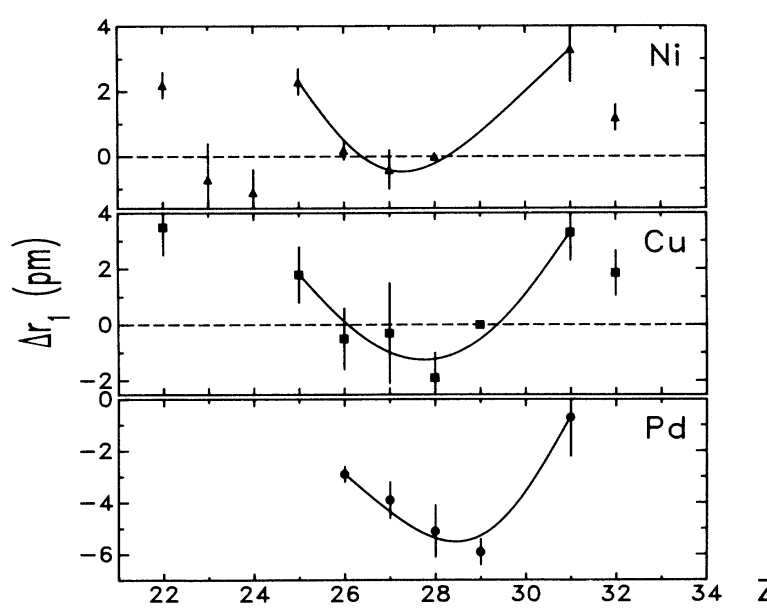

FIG. 9. Nearest-neighbor shift caused by first row impurities in the host metals $\mathrm{Ni}, \mathrm{Cu}$, and Pd measured by XAFS. The solid line is meant to guide the eye. contraction) is observed near nickel $(Z=28)$, while the reverse is true near the ends of the row of the Periodic Table. The same is found for second row elements (Fig. 10). The parabolic curve appears most pronounced for $\mathrm{Pd}$ and centers near Mo $(Z=42)$. This is analogous to the parabolic behavior of the cohesive energy (which is a measure for the binding of atoms in a solid), e.g., in pure $3 d$ metals. ${ }^{38}$ Similar observations exist for the metallic radii (or interatomic distances) in 12 coordinated pure metals. ${ }^{39}$ It should be noted that the minimum of the curve is found near the middle of the $4 d$ row (Fig. 10), while it is shifted to higher atomic numbers for $3 d$ elements (Fig. 9). This point will be discussed below. Finally, in Fig. 11 the results of heavy elements in the host metal $\mathrm{Pd}$ are shown. The rare-earth elements are clearly distinct from the $5 d$ group. While there appears to be a linear decrease for the lanthanides, again a parabolic curve is found for the $5 d$ elements. Both findings are roughly analogous to the behavior of the metallic radii. ${ }^{40}$ The two groups are separated by a drop of the lattice distortion upon going from $\mathrm{Lu}(Z=71)$ to $\mathrm{Hf}(Z=72)$. We will treat three theoretical models in order to discuss the experimental results.

\section{A. Continuous medium theory}

A simple approach is the assumption of a continuous isotropic elastic medium. The effect of the impurity atom is described by the Kanzaki forces $\mathbf{F}^{n}$ acting on the $n$th neighboring atom and creating just the same shift in the ideal crystal as the defect creates in the real crystal. The shift $\mathbf{S}(\mathbf{r})$ is expressed using the elastic Green's function $G_{i m}$ in the infinite crystal as ${ }^{41}$

$$
S_{i}(r)=G_{i m}\left(r-R^{n}\right) F_{m}^{n} .
$$

Here, and in the following, we assume summation over two identical indices. For a substitutional impurity in a cubic environment, Eq. (1) can be approximated by

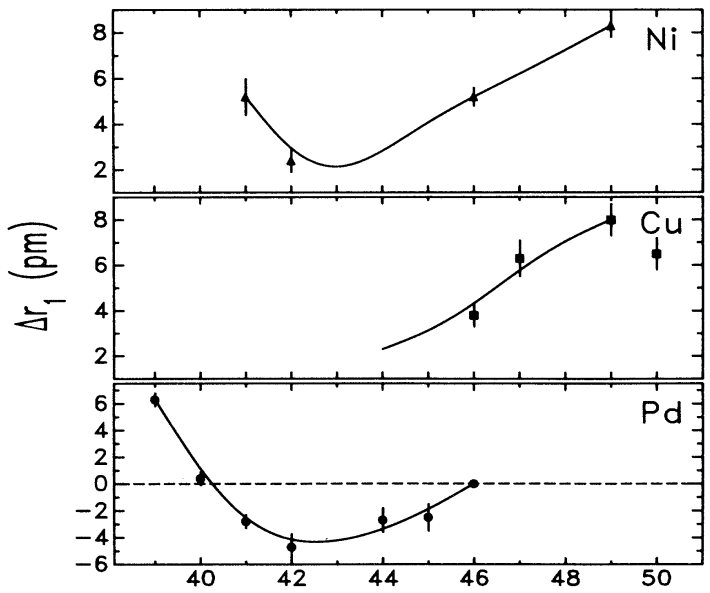

Z

FIG. 10. Nearest-neighbor shift caused by second row impurities in the host metals $\mathrm{Ni}, \mathrm{Cu}$, and Pd measured by XAFS. The solid line is meant to guide the eye. 


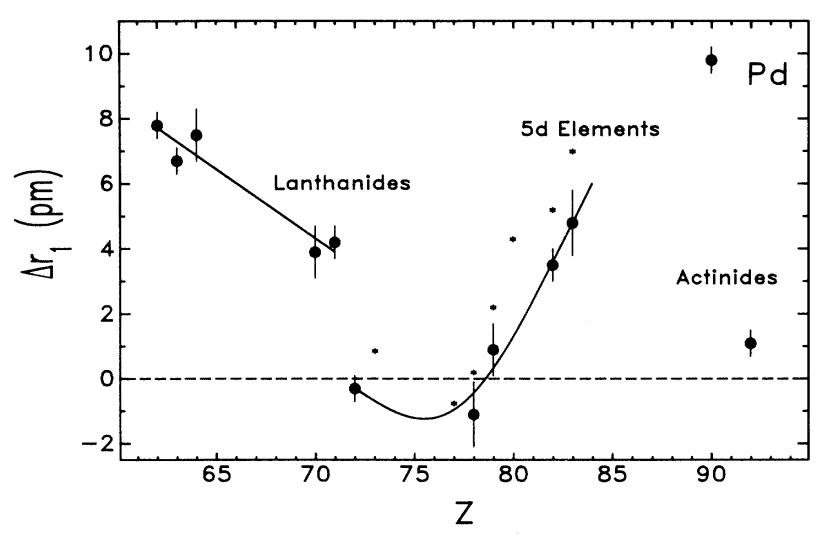

FIG. 11. Nearest-neighbor shift $(\bullet)$ caused by lanthanide, $5 d$, and actinide impurities in Pd. The solid lines are meant to guide the eye. For comparison, values derived from elastic theory $(*)$ are included (Ref. 23).

$$
S_{i}(r)=-P_{0} \frac{\partial}{\partial x_{l}} G_{i l}(r)
$$

with $P_{0} \delta_{l m}$, the dipole force tensor, which is the first moment of the Kanzaki force distribution. For cubic symmetry, the tensor reduces to a scalar. It can then be calculated from the volume size factor, $f_{\Omega}$. This factor is given by ${ }^{23} f_{\Omega}=(\delta \Omega / \delta c) / \Omega_{A}$, i.e., the rate of change of atomic volume with composition, normalized by the atomic volume of the solvent. According to Ref. 41, the following expression is derived:

$$
P_{0}=\frac{f_{\Omega}\left(c_{11}+2 c_{12}\right) a^{3}}{12}
$$

with the compression modulus, $\left(c_{11}+2 c_{12}\right) / 3$, and the lattice parameter, $a$. Combining the last two equations for $i=1$ (first neighbors) gives the following relation between the first-neighbor shift in a fcc lattice and the volume size factor:

$$
\Delta r_{1}=-\frac{f_{\Omega}\left(c_{11}+2 c_{12}\right) a^{3}}{12} \sqrt{2} G_{x l \mid l},
$$

where $G_{x l \mid l}$ is the appropriate derivative of the elastic Green's function. Equation (4) was used to calculate first-neighbor shifts from measurements of lattice parameters as a function of concentration ${ }^{6,23}$ (see Table I). The values of the Green's functions for the host metals $\mathrm{Al}, \mathrm{Ni}$,
$\mathrm{Cu}$, and Pd (Ref. 42) are listed in Table III.

The results for first row elements are shown in Fig. 12. there is good quantitative agreement with the XAFS data for the $3 d$ elements in $\mathrm{Ni}$ and $\mathrm{Cu}$. The parabolic behavior as a function of atomic number is obvious, in spite of some overestimation for the $4 s p$ elements. The agreement for the host Pd is very poor, the measured distortion is much larger. However, it has to be taken into account that the lattice-parameter measurements are more hampered by problems of clustering or alloy decomposition. This might explain some of the discrepancies. The general trend is reproduced for second row elements (Fig. 13) as well as for the $5 d$ elements (Fig. 11), using the data by King. ${ }^{23}$ The rather simple approach of the elastic theory gives a fairly good description of the local distortion of fcc lattices. The results are listed along with the XAFS results in Table $\mathrm{I}$.

\section{B. Eshelby analysis}

Eshelby ${ }^{43}$ has analyzed the problem of a compressible inclusion in an isotropic elastic matrix. The volume of the defect is larger by $\Delta V_{\text {loc }}$ than the volume of the matrix it replaces. The volume change induced by the defect at the surface is $\Delta V_{\text {fin }}$. For an elastically isotropic crystal, these terms are related via the Eshelby constant, $\gamma:{ }^{41}$

$$
\Delta V_{\text {fin }}=\gamma \Delta V_{\text {loc }}
$$

with

$$
\gamma=3 \frac{1-v}{1+v},
$$

where $v$ is the Poisson ratio $v=c_{12} / 2\left(c_{11}+c_{44}\right)$. The local volume change $\Delta V_{\text {loc }}$ is related to the normal displacement $S(r)$ according to

$$
\Delta V_{\mathrm{loc}}=4 \pi r^{2} S(r) \text {. }
$$

For first-neighbor shifts $\left(r_{1}=a / \sqrt{2}\right)$, the displacement is given by

$$
\Delta r_{1}=\frac{\Delta V_{\mathrm{loc}}}{4 \pi r_{1}^{2}}=\frac{\Delta V_{\mathrm{fin}}}{4 \pi \gamma r_{1}^{2}} .
$$

With the unit-cell volume $V_{c}=a^{3} / 4$, we derive

$$
\Delta r_{1}=f_{\Omega} \frac{\sqrt{2}}{8 \pi \gamma} r_{1} \text {. }
$$

The proportionality constant between $\Delta r_{1}$ and $f_{\Omega}$ in Eq. (9) can be compared to the results of Sec. IV A using Green's functions. For $\mathrm{Cu}(\gamma=1.545$, Ref. 44), Eq. (9)

TABLE III. Lattice constant (Ref. 8), $a$, compression modulus (Ref. 50), and Green's function (Ref. 42) for nearest-neighbor shift for fcc host metals at $77 \mathrm{~K}$.

\begin{tabular}{cclll}
\hline \hline Host & \multicolumn{1}{c}{$\mathrm{A} 1$} & \multicolumn{1}{c}{$\mathrm{Cu}$} & \multicolumn{1}{c}{$\mathrm{Ni}$} & \multicolumn{1}{c}{$\mathrm{Pd}$} \\
\hline$a(\mathrm{pm})$ & 402.9 & 360.4 & 351.6 & 388.2 \\
$\left(c_{11}+2 c_{12}\right) / 3(\mathrm{GPa})$ & 79.4 & 142.0 & 187.6 & 192.7 \\
$G_{x|l|}(1 / N)$ & $-6.74 \times 10^{6}$ & $-6.81 \times 10^{6}$ & $-4.12 \times 10^{6}$ & $-3.33 \times 10^{6}$ \\
\hline \hline
\end{tabular}




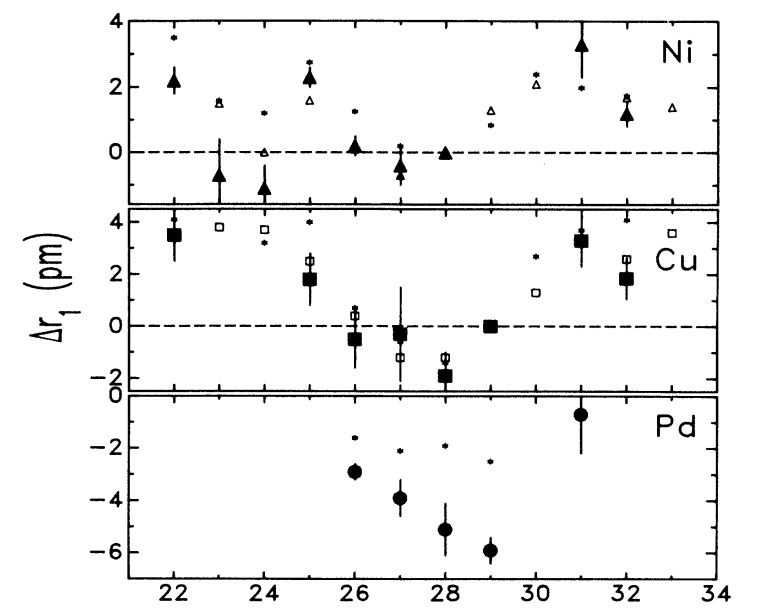

FIG. 12. Nearest-neighbor shift caused by first row elements in $\mathrm{Ni}, \mathrm{Cu}$, and Pd as measured by XAFS (solid symbols) and derived by band-structure calculations (open symbols) (Ref. 3) and from elastic theory $(*)$ (Refs. 6 and 23).

gives $\Delta r_{1} / f_{\Omega}=9.28 \mathrm{pm}$. From the Green's functions [Eq. (4)], $\Delta r_{1} / f_{\Omega}=16.01 \mathrm{pm}$ is derived. The Eshelby result is too small by a factor of about 1.8 due to the anisotropy of $\mathrm{Cu}^{44}$ For $\mathrm{Al}(\gamma=1.444$, Ref. 44$)$, which is more isotropic, the results from the Green's function [Eq. (9)] and Eshelby analysis differ by only $4 \%$.

Apparently, even the simple Eshelby approach can give a reasonable estimate for the first-neighbor shift. Both theories, however, are phenomenological only. More insight is obtained from $a b$ initio calculations.

\section{Band-structure calculations}

The shift of neighbor atoms is caused by defectinduced changes of the charge density, illustrating the

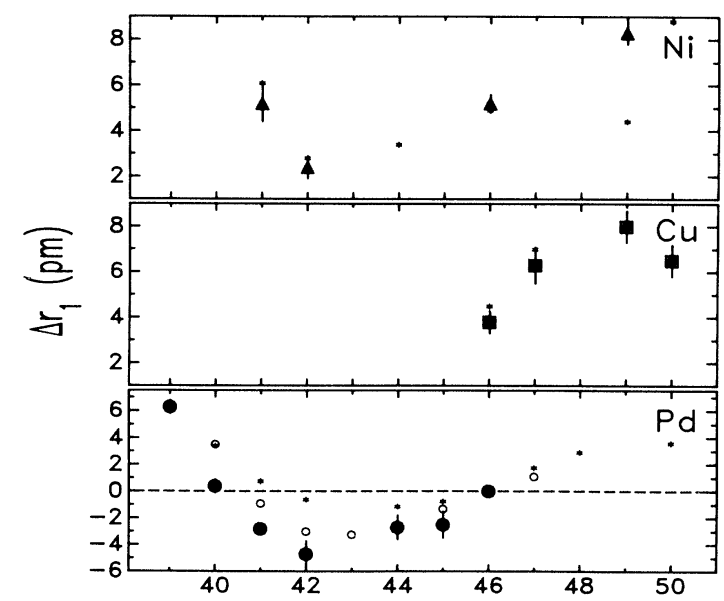

Z

FIG. 13. Nearest-neighbor shift caused by second row elements in $\mathrm{Ni}, \mathrm{Cu}$, and Pd as measured by XAFS (solid symbols) and derived by band-structure calculations (open symbols) (Ref. 3 ) and from elastic theory (*) (Refs. 6 and 23). connection between electronic and atomic structure. For the theoretical description of real systems, the quantummechanical treatment of a many-electron system is required. Improvements of the density-functional theory, the methods of band-structure calculations, and computational capabilities make it possible to treat point defects in metals. Based on the KKR Green's-function method, ${ }^{45,46}$ a procedure has been developed ${ }^{47-49,3}$ which allows one to calculate the forces on six neighbor shells of an impurity. The atomic shifts caused by the relaxation of these forces were calculated using harmonic lattice theory. ${ }^{3}$ Theoretical results are available for $3 d$ and $4 s p$ elements in $\mathrm{Cu}$ and $\mathrm{Ni}$ and $4 d$ elements in $\mathrm{Pd}$. These data are listed in Table I. For $3 d$ and $4 s p$ impurities in $\mathrm{Cu}$ and $\mathrm{Ni}$ (Fig. 12), there is generally good agreement with the XAFS results. For these host metals, the disturbance (i.e., the valence difference between host and impurity) is small, and the parabolic curve above $Z=25$ is well reproduced. Deviations from a simple parabolic shape in $\mathrm{Ni}$ for $Z \leq 25(\mathrm{Mn})$ are caused by magnetic effects. The magnetism of the impurity causes larger lattice distortions. This gives rise to a $w$-shaped curve with an additional maximum for $\mathrm{Mn}$. Even a small asymmetry in $\mathrm{Cu}$ can be explained by magnetoelastic interaction. ${ }^{3}$ Major deviations from the experimental values are found for the low- $Z$ elements $\mathrm{Ti}$ and $\mathrm{V}$. The atomic shifts are overestimated, most likely due to anharmonic effects or because the small-disturbance approximation does not hold. In Fig. 13, the results for $4 d$ elements in Pd are shown. Due to the absence of magnetic effects, a simple parabolic curve is observed in $\mathrm{Pd}$ with a minimum near the middle of the $4 d$ row, in good agreement with the XAFS results.

\section{CONCLUSIONS}

We have presented in this paper high-precision XAFS data of the lattice distortion around impurity atoms in 61 dilute alloys with $\mathrm{Al}, \mathrm{Ni}, \mathrm{Cu}, \mathrm{Pd}, \mathrm{Ag}, \mathrm{V}, \mathrm{Fe}$, and $\mathrm{Nb}$ matrices. The technique is ideally suited for that purpose due to its atom-specific character. It can be applied to almost any impurity atom in contrast to perturbed angular correlation or to Mössbauer spectroscopy. It has turned out that the first neighbor of an impurity in a metal can be shifted up to $10 \mathrm{pm}$ or about $3.6 \%$ of the interatomic distance. In general, the higher neighbor shells are shifted by much less than $1 \%$.

Over the last years, the quality of $a b$ initio calculations of electronic and structural properties has improved considerably. The present experimental data give an excellent test of the accuracy of these calculations. These, on the other hand, give an insight into the mechanisms responsible for the observed quantities. In the present case, two main contributions to the lattice distortion can be identified. The first one is due to the filling of bonding and antibonding orbitals with increasing $Z$ in a row of the Periodic Table. The second one is a magnetoelastic contribution most pronounced for magnetic impurities.

It is found that a phenomenological theory with Kan- 
zaki forces and Green's functions describe the relation between local lattice distortion and lattice-parameter changes in a satisfactory way. Although this description does not give the reasons for the distortion, it gives a good estimate of the local distortion when only latticeparameter changes are known.

\section{ACKNOWLEDGMENTS}

The authors would like to thank U. Dedek for help with the data acquisition. Dr. H. Schober for providing the Green's functions in Table III and Professor P. H. Dederichs for many helpful discussions.
${ }^{1}$ D. D. Koelling, Rep. Prog. Phys. 44, 139 (1981).

${ }^{2}$ O. K. Andersen, O. Jepsen, and D. Glötzel, in Highlights of Condensed Matter Theory, edited by F. Bassani, F. Fumi, and M. P. Tossi (North-Holland, New York, 1985).

${ }^{3}$ K. Abraham, diploma thesis, KFA Jülich, 1990 (unpublished).

${ }^{4}$ P. Villars and L. D. Calvert, Pearson's Handbook of Crystallographic Data for Intermediate Phases (American Society of Metals, Metals Park, Ohio, 1986).

${ }^{5}$ Structure Reports, edited by W. B. Pearson (Reidel, Dordrecht, 1940-1989), Vols. 8-56A.

${ }^{6}$ W. B. Pearson, Handbook of Lattice Spacings and Structures of Metals (Pergamon, New York, 1958), Vols. 1 and 2.

${ }^{7}$ M. Hansen, Constitution of Binary Alloys (McGraw-Hill, New York, 1958); R. P. Elliott, Constitution of Binary Alloys, 1st Suppl. (McGraw-Hill, New York, 1965); F. A. Shunk, Constitution of Binary Alloys, 2nd Suppl. (McGraw-Hill, New York, 1969).

${ }^{8}$ Structure Data of Elements and Intermetallic Compounds, edited by K.-H. Hellwege and A. M. Hellwege LandoltBörnstein, New Series, Group III, Vol. 6, (Springer, Berlin, 1971).

${ }^{9}$ Y. S. Touloukian, R. K. Kirby, R. E. Taylor, and P. D. Desai, Thermal Expansion-Metallic Elements and Alloys, Thermophysical Properties of Matter (Plenum, New York, 1975), Vol. 12.

${ }^{10}$ J. E. Müller, O. Jepsen, and J. W. Wilkins, Solid State Commun. 42, 365 (1982).

${ }^{11}$ K. D. Sevier, Low Energy Electron Spectrometry (Wiley Interscience, New York, 1972).

${ }^{12}$ B. Lengeler and P. Eisenberger, Phys. Rev. B 21, 4507 (1980).

${ }^{13}$ B. K. Teo and P. A. Lee, J. Am. Chem. Soc. 101, 2815 (1979).

${ }^{14}$ E. A. Stern and S. M. Heald, in Handbook of Synchrotron Radiation, edited by D. E. Eastman and Y. Farge (NorthHolland, Amsterdam, 1983), Vol. 1B.

${ }^{15} \mathrm{~B}$. Lengeler, Proceedings of the 4th International Conference on EXAFS and Near Edge Structures [J. Phys. (Paris) Colloq. 47, C8-75 (1986)].

${ }^{16}$ B. Lengeler, in Microstructural Characterization of Materials by Non-Microscopical Techniques, edited by N. Hessel Andersen, M. Eldrup, N. Hansen, D. Juul Jensen, T. Leffers, H. Lilholt, O. B. Pedersen, and B. N. Singh (Riso National Laboratory, Roskilde, Denmark, 1984).

${ }^{17}$ B. Lengeler and P. Eisenberger, in Decomposition of Alloys: The Early Stages, edited by P. Haasen, V. Gerold, R. Wagner, M. F. Ashby (Pergamon, Oxford, 1983).

${ }^{18}$ A. J. McAlister and J. L. Murray, Bull. Alloy Phase Diagrams 5, 341 (1984); 6, 111 (1985).

${ }^{19}$ T. B. Massalski, Binary Alloy Phase Diagrams (American Society for Metals, Metals Park, Ohio, 1987), Vol. 1.

${ }^{20}$ A. Kelly and R. B. Nicholson, Prog. Mater. Sci. 10, 151 (1963).

${ }^{21}$ E. Matsubara and J. B. Cohen, Acta Metall. 12, 2129 (1983).

${ }^{22}$ A. Fontaine, P. Lagarde, A. Naudon, D. Raoux, and D. Spanjaard, Philos. Mag. 40, 17 (1979).

${ }^{23}$ H. W. King, J. Mater. Sci. 1, 79 (1966).
${ }^{24}$ B. Lengeler and M. A. Pick, Solid State Commun. 53, 297 (1985).

${ }^{25}$ D. Raoux, A. Fontaine, P. Lagarde, and A. Sadoc, Phys. Rev. B 24, 5547 (1981).

${ }^{26}$ J. Mimault, A. Fontaine, P. Lagarde, D. Raoux, A. Sadoç, and D. Spanjaard, J. Phys. F 11, 1311 (1981).

${ }^{27}$ M. Marcus, Solid State Commun. 38, 251 (1981).

${ }^{28}$ R. Munch, H. D. Hochheimer, A. Werner, G. Materlik, A. Jayaraman, and K. V. Rao, Phys. Rev. Lett. 50, 1619 (1983).

${ }^{29}$ M. B. Stearns, J. Appl. Phys. 52, 1649 (1981).

${ }^{30}$ G. Renaud, N. Motta, F. Lançon, and M. Belakhovsky, Phys. Rev. B 38, 5944 (1988).

${ }^{31}$ J. B. Hastings, P. Eisenberger, B. Lengeler, and M. L. Perlman, Phys. Rev. Lett. 43, 1807 (1979).

${ }^{32}$ P. Weightman, H. Wright, S. D. Waddington, D.v.d. Marel, G. A. Sawatzky, G. P. Diakun, and D. Norman, Phys. Rev. B 36, 9098 (1987).

${ }^{33}$ A. Craievich, E. Dartige, A. Fontaine, and D. Raoux, in $E X-$ AFS and Near Edge Structure, edited by A. Bianconi, L. Incoccia, and S. Stripeich (Springer, Berlin, 1983).

${ }^{34}$ R. L. Cohen, L. C. Feldman, K. W. West, and B. M. Kincaid, Phys. Rev. Lett. 49, 1416 (1982).

${ }^{35}$ J. C. Mikkelsen and J. B. Boyce (unpublished).

${ }^{36}$ J. C. Mikkelson and J. B. Boyce, Phys. Rev. B 28, 7130 (1983).

${ }^{37}$ J. B. Boyce and J. C. Mikkelsen, J. Cryst. Growth 98, 37 (1989).

${ }^{38}$ V. L. Moruzzi, J. F. Janak, and A. R. Williams, Calculated Electronic Properties of Metals (Pergamon, New York, 1978).

${ }^{39}$ W. B. Pearson, The Crystal Chemistry and Physics of Metals and Alloys (Wiley Interscience, New York, 1972), and references therein.

${ }^{40} \mathrm{~K}$. A. Gschneidner and F. W. Calderwood, in Handbook on the Physics and Chemistry of Rare Earths, edited by K. A. Gschneidner and L. Eyring (North-Holland Physics, Amsterdam, 1986), Vol. 8.

${ }^{41}$ G. Leibfried and N. Breuer, Point Defects in Metals I, Vol. 81 of Springer Tracts in Modern Physics (Springer, Berlin, 1978).

42J. W. Deutz and H. R. Schober, Comput. Phys. Commun. 30, 87 (1983).

${ }^{43}$ J. D. Eshelby, J. Appl. Phys. 25, 255 (1954).

${ }^{44}$ P. H. Dederichs and J. Pollmann, Z. Phys. 255, 315 (1972).

${ }^{45}$ J. Korringa, Physica 13, 392 (1947).

${ }^{46}$ W. Kohn and N. Rostoker, Phys. Rev. 94, 1111 (1954).

${ }^{47}$ R. Zeller and P. H. Dederichs, Phys. Rev. Lett. 42, 1713 (1979).

${ }^{48}$ P. J. Braspenning, R. Zeller, A. Lodder, and P. H. Dederichs, Phys. Rev. B 29, 703 (1984).

${ }^{49}$ B. Drittler, M. Weinert, R. Zeller, and P. H. Dederichs, Phys. Rev. B 42, 9336 (1990).

${ }^{50}$ Elastic Piezoelectric, Pyroelectric, Piezooptic, Electrooptic Constants, and Nonlinear Dielectric Susceptibilities of Crystals, edited by K.-H. Hellwege and A. M. Hellwege, LandoltBörnstein, New Series, Group III, Vol. 11 (Springer, Berlin, 1979). 